\title{
Evaluation of various aqua suspension formulations of Beauveria bassiana (Balsamo) Vuillemin against Helicoverpa armigera
}

\author{
R.S. JADHAV ${ }^{1 *}$ AND S.D. PATIL ${ }^{2}$ \\ ${ }^{1}$ Department of Entomology, College of Agriculture, LATUR (M.S.) INDIA \\ ${ }^{2}$ Agricultural Research Station, Niphad, NASHIK (M.S.) INDIA
}

\section{ARITCLE INFO}

Received : 11.03 .2017

Revised : 24.08 .2017

Accepted : 06.09.2017

\section{KEY WORDS :}

Beauveria bassiana, Adjuvants, Glycerol (GLY), Honey (HO),

Sunflower oil (SFO), Groundnut oil (GNO), Tween 80 (TW),

Carboxymethyl cellulose (CMC), Boric acid (BA)

*Corresponding author: Email: rsjadhav187@gmail.com

\begin{abstract}
:
Studies on laboratory evaluation of nine aqua suspension formulations of entomopathogenic fungus, Beauveria bassiana (Balsamo) Vuillemin comprising adjuvants viz. 1) B.b.+GLY+CMC, 2) B.b.+GLY+HO, 3) B.b.+SFO+CMC 4) B.b.+SFO+HO 5) B.b.+GLY+BA, 6) B.b.+GLY+BA+TW, 7) B.b.+SFO, 8) B.b.+GNO and 9) Control (B.b. alone) were carried out against the II and III instar larvae of H.armigera. The data on larval mortality was recorded at 5, 7 and 10 days after treatment (DAT). At 10 DAT all the formulations were significantly superior to control (B.b. alone) for the lethal effect. The formulation B.b.+ SFO + CMC registered significantly highest larval mortality of 90.00 and 83.33 per cent of II and III instar larvae of H.armigera, respectively. However, it was at par to the formulation B.b.+ GLY + HO recording 86.67 and 80.00 per cent mortality of II and III instar larvae of H.armigera, respectively. The control $(B . b$. alone) recorded lowest (63.33 and $53.33 \%$ ) mortality of the caterpillar.
\end{abstract}

How to view point the article : Jadhav, R.S. and Patil, S.D. (2017). Evaluation of various aqua suspension formulations of Beauveria bassiana (Balsamo) Vuillemin against Helicoverpa armigera. Internat. J. Plant Protec., 10(2) : 354-359, DOI : 10.15740/HAS/IJPP/10.2/354-359.

\section{INTRODUCTION}

Microbial control is the biological suppression of insect pests employing microbial world. It has advantage of higher host specificity, virulence, safety to natural enemies, ease in mass production, multiple benefit in bioefficacy due to accelerating and spreading epizootics in pests, shelf-life and compatibility with other methods. More than 750 species of entomopathogenic fungi, representing 100 genera are currently known (Hajek and St. Leger, 1994). The entomopathogenic fungi causing diseases to the insects and are practically more significant as they are epizootic in nature. Also they have the advantage of ease of production and contact action which allow direct penetration of the host cuticle without ingestion.

Bassi (1835) was the first to demonstrate that entomopathogenic fungus; $B$. bassiana could cause an 